\title{
CORRECTING THINGS AS CORRECTING FEELINGS: A PHENOMENOLOGICAL STUDY OF WANG YANG-MING'S DOCTRINE OF GE-WU
}

\author{
MINGLAI DONG
}

\begin{abstract}
This article is designed to offer a phenomenological reading of Wang Yangming's (王陽明) doctrine of ge-wu (格物), which, as a part of Wang radical reading of The Great Learning (Da-Xue 大學), distinguishes his doctrine from that of Zhu Xi (朱喜). Wang argues that ge-wu, as rectifying things, is the same process with the act of cheng-yi (誠意), in which yi (意) and wu (物) form a relation of intentionality in Edmund Husserl's sense. Since for Wang, what can be made sincere are emotional yi such as liking and disliking, Husserl's phenomenology on emotional intentionality will be used in this article. The emotional intentionality is the unity of emotional noeses and valued noemata. For Wang, ge-wu is to change a wu improperly valued into a proper one, which is the same process of rectifying an immoral yi into a moral one.
\end{abstract}

Keywords: ge-wu, Husserl, moral efforts, phenomenology, Wang Yang-ming

\section{INTRODUCTION}

This article studies the sixteenth-century Confucian philosopher Wang Yang-ming's ( 王陽明 or Wang Shou-ren 王守仁)'s reading of the notion ge-wu (格物) from the Confucian classic The Great Learning (Da-Xue 大學). Wang revolutionarily challenged the so-called "Doctrine of Principle" or li-xue (理學) represented by Zhu Xi (朱喜) whose doctrine was the mainstream of the Neo-Confucian thoughts of Wang's time. Though Wang is often believed as an opponent of Zhu Xi, both thinkers share some understandings regarding the metaphysical foundation of human morality and the end of moral effort ( $g$ ong-fu 工夫). According to the Neo-Confucian tradition to which Wang and Zhu Xi belong, the purpose of the moral effort is to cultivate one's moral personality and to bring it to its highest state, namely, sagehood. What makes Wang and $\mathrm{Zhu} \mathrm{Xi}$ radically different is their doctrines regarding the methodology of gong-fu. Since Wang's reading of $g e-w u$ is crucial for his theory of

DONG, MINGLAI: Faculty member, College of Literature and Journalism, Sichuan University, China. Email: dongminglai@outlook.com 
moral effort, it deserves a careful study. In the next section, I will analyze the role that the moral effort plays for both Zhu Xi and Wang so that the significance of ge-wu for both can be clarified.

I argue that a phenomenological interpretation can clarify some difficulties confronted by Wang's theory of ge-wu. This strategy is possible, for there is a structural parallel between Wang's theory of yi (意) ${ }^{1}$ and Husserl's phenomenology of intentionality. Many scholars like Chen Shao-ming (陈少明) (2014), Iso Kern (1994 and 2010) and Chen Li-sheng (陈立胜) (2004) successfully applied Husserl's analysis of intentionality to some particular problems regarding Wang'sphilosophy, but a specific phenomenological study of Wang's doctrine of ge-wu is still wanted. What is specifically helpful for the purpose of this article is Husserl's description of feelings as a form of intentionality, which I will pay special attention to.

\section{THE ROLE OF THE MORAL EFFORT IN WANG YANGMING'S SYSTEM}

It is necessary to briefly study Wang's understandings of both moral effort and the metaphysical foundation of morality so that the differences between the theories of Wang and Zhu Xi can be clarified. Wang, as a Neo-Confucian, believes that morality should be based on some laws which Neo-Confucians name tian-li (天理), whose literal meaning is "the principle of the heaven." Wang maintains that such laws are valid standards of morality in all historical situations (Wang 2014, 225). For him, the most crucial tian-li is the principle of birth (sheng-sheng 生生), according to which one should love living beings with different degrees (Wang 1963, 222). ${ }^{2} \mathrm{He}$ also suggests that this principle of sheng-sheng is the same with the Great Ultimate (tai-ji 太極). According to the Neo-Confucian tradition, tai-ji is the foundation of the whole universe (Wang 1963, 136). That is to say, tian-li are also principles of the world itself. Tian-li within Wang's system, as the foundation of morality, are generally the same with those of Zhu Xi. Zhu Xi also argues that tian-li are the same with the Great Ultimate, and the physical motions of nature itself must follow these laws (Zhu 1986, 1-3). Nature gives life to living beings through the changes of seasons, for it follows tian-li (Zhu 2015, 180).

More importantly, Wang and Zhu Xi have some similar understandings regarding the relation between xin and tian-li. Wang famously asserts that all principles are internal to xin (Wang 1963, 7) so that one does not need to seek morality from things external to his or her $x i n$. Such principles are in $x i n$ as its "original substance (ben-ti 本體)", or as its original talent (Wang 2014, 1302). Wang claims, "The origin of the good is the xing (性), ${ }^{3}$ which is named by Mencius as the good nature.... What is in

\footnotetext{
${ }^{1}$ This notion is often translated as "thought".

${ }^{2}$ In this article, pages and chapter numbers of Chuan-Xi- $L u$ are given according to Chan's translation (Wang 1963).

3 The literal meaning of this character is "the nature of different things".
} 
xing is the good. These are different names, while actually, they are all (referring to) xin" (Wang 2014, 175). For Wang, xin contains principles in the form of xing, which, according to Mencius, is naturally good. Wang accepts Mencius's position and argues that ben-ti of xin, as the "location" of xing, contains nothing immoral (Wang 1963, 52). Wang also realizes that people are having evil deeds and thoughts all the time. I will briefly address this issue very soon.

Wang's theory of xin can be expressed by his famous slogan that " $x i n$ is principles." Zhu $\mathrm{Xi}$, on the other hand, is considered to base his theory on the statement that "xing (性) is principles" (Zhu 2015, 17). It seems that Zhu Xi only emphasizes xing but does not trust xin. However, Zhu Xi often claims that he agrees with Zhang Zai (張載)'s doctrine that “xin unites xing and feelings (心統性情).” In other words, for Zhu Xi, xing is not separated from xin. He argues that "xin takes xing as its substance, and xin contains xing as its stuffing (xian-zi 餡子)" (Zhu 1986, 89). Xing is a "special part" of xin, as Zhu Xi explains more elaboratively in the following paragraph:

The original substance of xin... has every principle incomplete, and does not have an iota of selfish desire.... Hence, when talking about its complete substance which has not been aroused, it is xing. When talking about its subtle usage as that which is aroused, it is feelings. However, the doctrine that "xin unites xing and feelings" is only referring to the difference between the state before xin is aroused, and the state after it is aroused. It is not saying that there are different things as xin, xing, and feelings. They are not separated in this sense. (Zhu 1986, 94)

It is quite apparent according to this quotation that Zhu Xi's understanding of the original substance of xin is almost the same as that of Wang. Like Wang, Zhu Xi believes that the original substance has all tian-li as its contents, and serves as the condition for one to have proper feelings. Xing is contained in xin as the ben-ti, whose function can be described as the original capability of xin, though this capability may be concealed. ${ }^{6}$ Both $\mathrm{Zhu} \mathrm{Xi}$ and Wang point out that despite the original substance, $x i n$ is also the only subject of evil deeds. It is well-known that according to $\mathrm{Zhu} \mathrm{Xi}$, "xin has good and evil, but xing has nothing that is not good" (Zhu 1986, 89). This claim seems to be opposed to his theory of ben-ti of xin. However, what is evil does not arise from the original substance (Zhu 1986, 86): evil deeds stem from the so-called "selfish desires (si-yü 私慾)", which, according to Zhu $\mathrm{Xi}$, disable the original substance from functioning. Such desires are results of materials ( $q i$ 氣), rather than $x i n$. Zhu Xi's position is also similar to the opinion of

\footnotetext{
${ }^{4}$ Zhu Xi's emphasis on this statement of Zhang Zai was discussed thoroughly by many Chinese scholars. See Chen 1986, Cai 1991, and Cheng 2014.

5 心之全體‥萬理俱足, 無一毫私慾之間…故以其未發而全體者言之, 則性也; 以其已發而妙 用者言之, 則情也。然 “心統性情” , 只就渾淪一物之中, 指其已發、未發而言爾; 非是性是 一箇地頭，心是一箇地頭，情又是一箇地頭，如此懸隔也。

${ }^{6}$ For more discussions on Zhu Xi's understanding of ben-ti, see also Xiang 2012, and Zhao 2017.
} 
Wang, who explicitly claims that some immoral desires called selfish desires can conceal the original substance, and prevent xin from acting following its ben-ti (Wang 1963, 52). The obstruct of of si-yü is the reason why people cannot avoid immoral feelings, though they originally have the moral ability in their xin.

This grasp of the relation between ben-ti and si-yü also leads to the similar ideas of Zhu Xi and Wang, regarding the end of the moral effort. They argue that gong- $f u$ is to help xin regain the power of its original substance. More interestingly, they borrow the same metaphor to portray this process. Zhu Xi mentions many times that xin of a sage is like a mirror. This mirror is completely clean, for the xin of a sage is not troubled by si-yü (Zhu 1779, 49:15A-15B; 67:5B-6A). One whose $x$ in is a bright mirror is a sage, for he or she can always follow tian-li as the original contents of his or her xin. ${ }^{7}$ As Zhu Xi suggests, for people who are not sages yet, selfish desires are dust and rusts on their xin as mirrors. The task of the moral effort of such people is to "wipe" out dirt on xin as the mirror so that the "mirror" can recover its original brightness (Zhu 1986, 263; 267; 781; 787).

I spent several paragraphs on the similarities between Wang and $\mathrm{Zhu} \mathrm{Xi}$, for this can shed light on the reason for which Wang pays so much attention to a new interpretation of $g e-w u$ : this notion plays a vital role in the methodologies of moral effort of both thinkers which radically differ from each other. It is well-known that according to $\mathrm{Zhu} \mathrm{Xi}, g e-w u$ is the first one of the eight steps of moral effort mentioned in Da-Xue (Zhu 2015, 3-4). In this Confucian classic, there are eight items that are important for one's life: ge-wu, zhi-zhi (致知), cheng-yi (誠意), zheng-xin (正 心), xiu-shen (脩身), qi-jia (齊家), zhi-guo (治國), and ping-tian-xia (齊家) (Zhu, $2015,3){ }^{8}$ The first five items are internal to a person and should be the "roots" for the other three. Zhu $\mathrm{Xi}$ treats all these tasks as different kinds of activities, which should be ordered temporally: only one who has finished the process of ge-wu and $z h i-z h i$ can begin the process of cheng-yi. In Zhu Xi's view, the character "ge (格)" is to investigate thoroughly, and to ge-wu is to study nature itself as a whole (Zhu 2015, 4). This process of $g e-w u$ is identified with $z h i$-zhi which Zhu Xi reads as the extension of one's knowledge of the world. Note that for the Neo-Confucians, knowledge of this world is also the knowledge of tian-li. Therefore, Zhu Xi believes that the process of ge-wu and $z h i-z h i$ also has an ethical significance. Such knowledge of the world and tian-li is the necessary condition for the moral effort: $\mathrm{Zhu} \mathrm{Xi}$ maintains that since ben-ti of $x i n$ is concealed, ben-ti cannot function as the guide for the moral effort. Gong-fu should follow the guidance of the knowledge that can be learned even when the original substance of one's xin is obstructed by si-yü (Zhu 1986,161). Zhu Xi often suggests that to bring xin back to its original brightness, one

\footnotetext{
${ }^{7}$ Zhu Xi's use of the mirror metaphor has also been realized by many scholars. For example, see Xiang 2012 and Zhao 2018.

${ }^{8}$ Literally, the seven terms from zhi-zhi to ping-tian-xia mean to extend one's knowing, to make one's $y i$ sincere, to rectify one's xin, to cultivate one's body, to give order to one's family, to rule one's state properly, and to bring peace to the whole world.
} 
should begin from reading Confucian classics, for such texts contain all necessary knowledge in a Confucian sense.

Zhu Xi's account of ge-wu in the moral effort is the point that can distinguish his doctrine from that of Wang. Zhu Xi believes that ge-wu should be temporally prior to cheng-yi as a process of making $y i$ ethical. Wang rejects both Zhu Xi's reading of "ge" and Zhu Xi's doctrine regarding the relation between ge-wu and cheng-yi. He claims that "to ge is to rectify. It is to rectify that which is incorrect so that it can return to the correctness" (Wang 1963, 55). Ge-wu is not an investigation of things as an attempt to grasp knowledge, but a process of rectifying incorrect $w u$. This reading raises two issues: (1) What is the meaning of the term "correct wu"? (2) What is the structure of this process of rectifying things for moral effort? An immediate response to these questions is Wang's understanding of the relation between ge-wu and cheng$y i$, as is expressed in the following paragraph:

I interpret the word ge as rectifying and $w u$ as affairs or events.... In xin's operation, it is impossible for it to be entirely free from evil. Therefore, we must make our efforts here (when xin is evil). This means to make yi sincere. For instance, when intending to love what is good, love what is good truly and concretely. When intending to hate what is evil, hate what is evil truly and concretely. (Wang 1963, 247-248)

According to this quotation, though the character “cheng (誠)" originally means "honest", what is not sincere in the term cheng-yi is a $y i$ that is evil, rather than dishonest. A xin whose ben-ti is concealed will have immoral yi. Wang believes it is not easy (or even impossible) to directly touch xin itself, so that "we can make our effort only in (the case) when xin is aroused" (Wang 2014, 1294). In the next section, I will demonstrate that within Wang's system, when xin is aroused, $y i$ is diffused from it. That is to say, to directly deal with immoral $y i$ is the real effort of "polishing the mirror". This process is nothing but cheng-yi, namely, to rectify an immoral yi into a moral one. Later in this article, it will be shown that according to Wang, an evil yi is intrinsically connected with a $w u$ that is not correct. To rectify an incorrect thing is the same as amending an evil yi. In this sense, cheng-yi and ge-wu are always interwoven and are fundamental for the moral effort.

Readers who are familiar with Da-xue will wonder the role that zhi-zhi plays in Wang's theory. I address this issue in the last section of this article. What should be studied first is the relation between $y i$ and $w u$ upon which Wang builds his account of ge-wu and cheng-yi. This relation is a relation of intentionality in Edmund Husserl's sense. Thus, a phenomenological study of ge-wu and cheng-yi is possible. To offer an account for this possibility of studying Wang is the task of the next section.

\section{THE $Y I-W U$ RELATION AS A RELATION OF INTENTIONALITY}

For the purpose of clarifying Wang doctrine of ge-wu which is essentially inter- 
woven with cheng-yi, it is necessary to briefly study his theory of the $y i$-wu relation as a relation of intentionality.

According to Husserl, intentional acts of consciousness (noesis) and intentional objects (noema) are necessarily correlated. There are no noetic experiences without noemata, nor noemata without being intentionally experienced. Within his framework of intentionality, consciousness is a complex structure which contains both the noetic and the noematic sides (Husserl 1984, $\mathrm{B}_{1} 372 ; 2001,2: 98$ ). The way through which noemata and noeses are correlated is constitution: noemata are constituted by noeses of consciousness. This structure of constitution is crucial for the study of $g e-w u$ in this paper. Also, within Husserl's phenomenology of intentionality, noeses are not scattered pearls but are linked together in a necklace named as the ego. The ego functions as the chain of the necklace because all these pearls are "made" by it: they are rays "radiated" from xin as the single and integrated "light source" (Husserl 1952, 98 and 1989, 104). Acts as rays all "come from the same place," which makes them belong to the same "owner," namely, the ego. Since the intentionality is the unity of noeses and noemata, noemata are also "objects for the ego", via the media of noeses radiated from the ego.

The relation between $y i, w u$, and $x i n$ is almost the same with the intentional structure of noeses, noema, and ego. As Wang famously states, "What is diffused from xin is $y i \ldots$ and what is directed towards by $y i$ is a $w u$ " (Wang 1963, 14). Here, xin is the subject of "looking, listening, speaking, and motion" (Wang 1963, 80). Note that "looking, listening, speaking, and motion" are not physical movements of the body, for xin in Wang's system "is not merely that lump of blood and flesh" (Wang 1963, 80), but is "the clear and intelligent master of the body" (Wang 2014, 1069; 1963, 276). According to Husserl, the ego is also a subject of perceiving, judging, feeling, and willing, which are not instinctive reactions belonging to a body, but are acts belonging to the spiritual, mental stream of an ego (Husserl 1952, 97; 1989, 103). Both ego and xin serve as the subject of consciousness and are both identical, subjective poles for acts of consciousness. In Wang's view, yi are diffused from xin. I translate the Chinese character " $f a$ (發)" as diffuse. It is translated as "operate" by Wing-tsit Chan and as "stir" by Ivanhoe (Ivanhoe 2009, 168-169). While both of them have grasp this term correctly, it means to diffuse or project arrows with a bow originally in Chinese (Xu 1981, 270). This original meaning of " $f a$ " is still alive in Wang's philosophical usage of it. When xin is looking, looking is a yi diffused from $x i n$. Xin is the bow, and different $y i$ are arrows projected by this bow. In this sense, one's $x i n$ binds together all of his or her $y i$.

Targets of such arrows are $w u$, often translated as "things." Wang maintains that "Yi never hangs in a vacuum. It is always connected with some $w u$ or shi (事)" (Wang $1963,189)$. This quotation obviously means that there are no $y i$ without $w u$. $W u$ are targets of $y i$. Using terms of Husserl, $w u$ are "objects of $y i$ " or "noemata of $y i$." Since all $y i$ are radiated from $x i n$, all $w u$ that are targets of $y i$ can also be treated as "things for xin." This again reminds us of Husserl's phenomenology of intentionality, according to which all noeses are from the ego, and all noemata constituted by noeses are "neomata for the ego." Many scholars have realized this similarity between 
structures of Wang and Husserl. As Jung Hwa Yol pointed out in 1965, yi, as "the activity of hsin", is "an intentional act in the widest sense... that is best described as 'intentionality' in the phenomenological sense" $(2002,44)$. Chen Lai (陈来) also realizes that the function of $y i$ for Wang is similar to that of noesis in Husserl's system, and the role of $w u$ is similar to that of noema (2009, 60-61). After the first publication of Chen Lai's book in 1980, many other scholars, under the influence of Chen Lai, have also attempted to apply the phenomenological method to Wang's doctrines. The observations of Jung and Chen Lai are undoubtedly correct, but there are some necessary clarifications regarding existing phenomenological studies of Wang Yangming.

Scholars like Chen Li-sheng, Chen Shao-ming and Zhang Zai-lin (张再林) who adopt Chen Lai's strategy claim that in the statement "whatever is targeted by the intention is the $w u$," "wu" can only refer to affairs such as respecting one's elders (Chen 2009, 167; Chen 2014b, 69-70). Though their studies have some solid textural proofs, these scholars are problematic in other ways. That the term "wu" can signify "affairs" cannot lead to the conclusion that it only has this meaning. It may have more than one meanings. This possibility is recognized by Mou Zong-san (牟宗三), one of the most important figures of the twentieth-century Neo-Confucian school. Mou defines Wang's term “affair" as “an act of life” (sheng-ming-de-xing-wei 生命的行為 ) such as using a table. However, this act also has its object, namely, the table. Mou and his student Cai Ren-hou (蔡仁厚) both doubt whether the table itself is a wu within Wang's framework (Mou 2003, 202; Cai 1983, 66-67). There are two materials that can serve as clues for their questions:

1. Xin is naturally able to know. When it perceives the parents, it naturally knows that one should be filial. When it perceives the elder brother, it naturally knows that one should be respectful. (Wang 1963, 15)

2. When it diffused from xin, we have filial piety when it meets the father, loyalty when it meets the lord, and so on to infinity. (Wang 1964, 34)

According to these two quotations, xin perceives or meets parents, brothers, and lords. They are human beings whose "mode of being" is more similar to that of external beings such as tables, rather than that of affairs or "acts of life." Note that according to Wang, the act of perceiving is a $y i$, namely, an act of xin as nthe ego of consciousness. In Mou's words, to respect one's elder is an "act of life" similar to the action of using the table, so that the role of the elder in the act of respecting is similar to the role of table in the action of using. Since the elder can be the target of xin through the $y i-w u$ schema, the table is also a $w u$ in the same sense. It has to be emphasized that for Wang, the perceiving of a thing is not an action of the body, but is a $y i$ of xin, while Mou's term "act of life" has both meanings. To use a table is an action of the body, while to respect one's parents is an act of consciousness. Though Mou does not make a phenomenological clarification of his term, his question can still lead to the conclusion that for Wang, things in an everyday sense like tables can also be treated as $w u$, namely, as noemata in a Husserlian sense. 
Though scholars like Chen Lai are correct when they realize that affairs can be $w u$, their interpretations of " $w u$ " itself are to some extent too narrow, when they claim that this term can only refer to affairs. There is, however, a more interesting account in an existing study that can shed light on my project here and can also lead us to the topic of the next section, namely, the phenomenological structure of emotional yi.

\section{HUSSERL'S ANALYSES OF FEELING AS A FORM OF INTENTIONALITY}

In his article studying Wang Yangming's theory of intentionality, Chen Shao-ming argues that for Wang, xin does not function as a "simple mirror", but as a camera used by an artist. According to Chen, a $w u$ for a xin is not "displayed in a window" as it is, but is always grasped with social, aesthetical, or ethical meanings (Chen 2014b, 7476). Chen correctly points out that the focus of Wang, who as a Confucian, should be things that have ethical meanings. As "objects of the camera of an artist", $w u$ are noemata of xin which have some "emotional colors". With the help of Husserl's analysis of emotional noeses, the structure of such "emotional colors" can be better described.

Husserl's analysis of emotional noeses is based on his theory of constitution, according to which all noemata are constituted by the ego through its noeses. Within this process of constitution, an intentional object with specific properties is constituted by what Husserl names as sense-bestowal. A "sense" as an essence of something is bestowed upon the underlying flow of raw sensuous materials on the side of the act, named as the hyletic flow. An apple is an object with properties of shapes, colors, smells, touch, etc. These properties are correlated with materials like color-data, smell-data in the hyletic flow on the side of the act. Such materials are "used" by the essence of apple as the "sense", or as the "form" of such materials."

There are different forms of sense-bestowal, but these forms all have a hierarchical structure that is transcendental. According to Husserl's Ideas I that was published in 1913, a noema can have different levels, among which the level of a mere identification is the "lowest" one. This part of a noema is built by the level of noesis which bestows the sense of "a mere object which is identified with itself" (Husserl 1950, 189; 1998, 221-222). Without this simple self-identification, it is impossible to say that something is this or that. In Logical Investigations published over a decade before Ideas $I$, this fundamental layer of an act is also named as "presentation" (Husserl, 1984, B $1480-481 ; 2001,2: 160$ ). The mere presentation constitutes a "mere this" (Husserl, 1987, B1485 and 2001, 2:163). As the fundamental layer, it is necessary for every more complicated act which contains a "higher layer" (Husserl 1987, $\left.\mathrm{B}_{1} 441 ; 2001,2: 136\right)$. Such more complicated acts with multiple noetic layers can constitute noemata with more noematic layers. A noema which is "more than a mere thing" is named by Husserl as a "full noema" in Ideas I (Husserl 1950,

\footnotetext{
${ }^{9}$ For more elaborated phenomenological studies on this material-form schema, see Sokolowski 1984 and Zahavi 2003, 22-27.
} 
189 and 1998, 221). This noema contains the "mere thing" as a part of itself, and this "mere thing" serves as the "object simpliciter," or the "core" of the full noema. Upon this simpliciter, other noematic properties can be added, removed, or changed.

The particular form of noeses in point, namely, emotional acts, is also more complicated than and is founded on the mere presentation. As Husserl argues in Logical Investigations, "Whether we turn with pleasure to something, or whether its unpleasantness repels us, an object is presented" (Husserl 1984, $\mathrm{B}_{1} 389 ;$; 2001, 2: 108). In the same part of the book ("Fifth Investigation"), he further claims that feelings, as intentional acts, are impossible without a presentation, and a feeling contains the presentation as a fundamental layer of it. The feeling includes both a layer of presentation and a higher layer. In Ideas I, Husserl also insists that in the "emotional and volitional sphere", there is a "non-selfsufficient moment... stratified on a concrete process of simply objectivating..." (Husserl 1950, 197; 1998, 231). An emotional act is not self-sufficient because it cannot be performed only with itself: it must be founded on a presentation and can also be "removed" from it. In Logical Investigations, Husserl agrees with Brentano's claim that the "presented object" can be separated from the "felt object", while the latter is not separable from the former (Husserl 1987, $\left.\mathrm{B}_{1} 389 ; 2001,2: 107\right)$. Here, "object" refers to noema. Thus, when citing Brentano, Husserl is saying that it is possible for a "mere thing" to be presented without an "emotional color", whereas a noema with such a color cannot be independent of the presented simpliciter. This further implies that the same "mere this" given by the same presentation can be treated differently by different emotional acts: it can be loved, or be hated.

As many scholars have realized, feelings and values are essentially connected in Husserl's analysis. ${ }^{10} \mathrm{He}$ asserts in his lecture on ethics given in 1914 that an "emotional consciousness" is also a "universal valuing consciousness" (Husserl 1988, 86). This relation between emotions and values can be seen more clearly in the following quotation from Idea I:

In the noema belonging to the higher level the valued as valued is possible, a core of sense surrounded by new posited characteristics. The "valued," the "likable," "happy," etc. ... (Husserl 1950, 240; 1998, 277)

According to this quotation, values belong to the noematic side. The noema with value has a higher noematic property which makes the noema a full noema (Husserl 1950, 198-199; 1998, 232). ${ }^{11}$ This paragraph discussing valued object is cited from section 95 of Ideas I, whose title is "The Analogous Distinctions in the Emotional and Volitional Spheres". Also, in Husserl's 1914 lecture, a pleasant situation is presented with a "rosy light," and a displeasing scene is with a "gloomy light" (Husserl 1988, 86). A pleasant situation is a noema that is correlated with an emotional noesis of liking, so that "emotional colors" are noematic properties of different situations as

\footnotetext{
${ }^{10}$ See Hart 1992, 224-9; Loidolt 2012, 10f; Peucker 2007, 312; and 2008, 315 f.

${ }^{11}$ See also Zhang and Xu 2009, 136-138.
} 
"full noemata". Since Ideas I was published in 1913, it is reasonable to argue that values described in this book are treated by Husserl as equivalent to emotional colors mentioned in the 1914 lectures. The liking, as an act with a higher noetic layer, constitutes an object with a property on a more upper noematic stratum, which is nothing but a positive value.

Since phenomenological acts and objects are always correlated through the relation of constitution, a "full-noema" will also be changed, if its correlated full act is changed. When the liking as an act is changed into a disliking, the noema with a positive value is also changed into an intentional object with a negative value. A loved painting and a hated painting are different full noemata, though it is the same "mere painting" that is loved or hated. The "same painting" is constituted by the same act of presentation, and the different paintings are constituted by different emotional acts. Note that when an act of liking changes into an act of disliking, the correlated object not only stops "being liked," but also lose the value of being good.

\section{HUSSERL'S REJECTION OF AN ETHICAL RELATIVISM}

For Husserl, the most elemental act of ethical life is the emotional act which constitutes an object with a value-property. This theory may be interpreted as a form of relativism. People may argue that since all valued noemata are constituted by particular egos, such values are only values "for these egos," which means that there are no objective standards for good and bad. For example, Hobbes believes that what is good in an ethical sense is nothing but something that is physiologically pleasing (Hobbes 1994, 27-29). Since whether something can offer physiological pleasure is determined by biological features of one's body, there can be no ethical standards that are shared by all transcendental egos.

Husserl himself rejects this form of relativism. He believes that though a good noema is indeed constituted by ego as something that is "good for me", this value of being good should be universal for all egos if its correlated noesis is moral. Such an ethical noesis can constitute an object with a universal value, for it follows some forms of moral laws that Husserl names as axioms or "axiological laws". Such laws are "those which establish that the value can be treated as a predicate, as the presumption" (Husserl 1988, 86). ${ }^{12}$ More importantly, Husserl claims that "Only axioms of the previously determined essence can make it possible to define something "valuable" as a predicate objectively" (Husserl 1988, 86) ${ }^{13}$ Here, the "substance" to which a value as a "predicate" attaches is a noema. The implication is that a "predicate" is a noematic property as a part of a full noema. As was mentioned above, a "sense" in a sense-bestowal is an essence or a meaning. When a noema is valued, an "essence" of the value is bestowed as the sense. It is the universal essence of being good that determines whether a particular noema can be liked, and essences

\footnotetext{
12 "diejenigen, welche feststellen, daß Wert als Prädikat behandelt werden könne."

13 "Erst Axiome der vorhin festgestellten Art mach es, daß so etwas wie ,wert' objektiv als Prädikat definiert werden kann."
} 
of being good, being bad, being harmful, are all "defined" according to ethical axioms.

A noesis which bestows the sense of value is an emotional act. Hence, according to Husserl, feelings, as noises, should also follow ethical axioms. He maintains that "pleasure and sorrow here are rationally motivated acts" (Husserl 1988, 86). ${ }^{14}$ If a particular situation is good according to the essence of being good and the ethical axioms, then all egos ought to be pleased by this situation, which means that they ought to love this situation. One who does not act emotionally by such axioms is acting improperly in an ethical sense, i.e., he or she is acting immorally. Husserl argues that one will also be demanded by axioms to feel sorry in some cases. Hence, both the liking that constitutes a "positive" noema and the disliking correlated with a "negative" object can be rational and moral. An object which has a negative valueproperty may be disliked appropriately, from the perspective of ethical axioms. This function of the ethical axioms is essential for the task of this article, for the form of the relation between axioms and particular ethical noeses, are the same with the connection between tian-li and particular yi of liking and disliking according to Wang, as will be shown later.

For Husserl, a noema can be properly good, improperly good, properly bad, or inappropriately bad, according to the ethical axioms. This leads to the conclusion that if an improper emotional act is changed, then its correlated valued object is also made proper. This insight can shed light on Wang's doctrine of ge-wu.

\section{WANG'S THEORY O EMOTIONAL YI TOWARDS VALUED $W U$}

In the previous section, I studied Husserl's analyses of sense-bestowal and emotional intentionality as a specific form of sense-bestowal. All intentional objects are "for the ego", for they are constituted by acts of the ego. For Wang, a yi is a noesis so that the relation between $y i$ and $w u$ is also a relation of constitution. Some scholars have also realized this possibility, though they did not know Husserl at all. For example, Liang Qi-chao (梁啟超), one of the most influential Chinese scholars of the late nineteenth and early twelfth century, suggests that according to Wang, "without being intended, even the name 'equilateral triangle' would not exist, and this (particular) triangle would not either" (Liang 1968, 19). Liang's interpretation will make more sense from a phenomenological perspective: the name of the triangle expresses the essence, the "sense" of the triangle. To constitute a triangle as a noema, this sense of the triangle should be bestowed. Using Mou's examples mentioned in Section 3, when a person perceives the table or the parents, the essences of table, parents and lords should also be bestowed like the sense of triangle.

It is possible to maintain that for Wang, $w u$, including affairs and things like tables, are also constituted by their correlated $y i$, for $w u$ are nothing but noemata. This phenomenological reading of the $y i$ - $w u$ relation can illuminate Wang's understanding of "a correct thing." In a quotation that was cited in Section 2, Wang describes a

14 "Freude und Trauer sind hier vernünftig motivierte Akte." 
sincere $y i$ as "to love what is good and to hate what is evil" (Wang 2014, 263-1644, and 1963, 247-248). To make yi sincere means that one should correctly love what ought to be good and hate what ought bad. This statement implies that yi that should be made sincere are acts such as loving or hating as emotional noeses. Within Wang's framework, such noeses are also correlated with valued objects. In a crucial chapter of Chuan-Xi-Lu, Wang and his students discuss how to like or dislike grass. Xue Kan (薛㑆), the recorder of this dialogue, wants to "pull weeds among the flowers". Xue Kan treats grass as evil and flowers as good, and wonders why in nature "the good is difficult to be cultivated and the evil is difficult to be removed". Wang points out that Xue Kan is misguided by himself from the very beginning:

The spirit of life of heaven and earth is the same in flowers and weeds. Where have they the distinction of good and evil? When you want to enjoy flowers, you will consider flowers good and weeds evil. When you want to use weeds, you will then consider them good. Such good and evil are all products of xin's likes and dislikes. Therefore I know you are wrong. (Wang 1963, 63)

Wang argues that the distinction between good and evil made by Xue Kan is improper, for it is unnatural. Note that this does not mean that no such differences are natural. We mentioned in Section 2 that tian-li, as moral laws, are also proper standards of good and evil. When criticizing Xue Kan, Wang is only saying that Xue Kan's particular distinction does not follow tian-li. Wang's comments on Xue Kan's thoughts remind us of Husserl's study of particular emotional noeses and the ethical axioms mentioned in the previous section. I will return to this similarity later in this section.

A more important claim made by Wang in the quotation above is that it is Xue Kan's liking that makes the flowers good and his disliking that makes the grass evil. The specific noematic property that is constituted by an act of disliking is not merely "the property of being disliked", but is the value of being bad. Hence, being evil is a noematic property of the grass constituted by Xue Kan's disliking of it. This grass is bad for Xue Kan, though if it is properly liked or disliked, then it should be good or evil for all people. Note that Wang also points out that the grass will be constituted as good by Xue Kan when he wants to use it. That is to say, the grass itself is a presented "mere thing," upon which a value-property can be added, changed, and removed. A pile of grass as a thing is constituted by a $y i$ of seeing, whose function is similar to the function of the presentation within Husserl's theory. Xue Kan treats the same pile of grass as good when he wants to use this grass, and treats it as bad when it is troubling the beautiful flowers. This indicates that liking or disliking as intentional acts are different from the $y i$ which presents the same "mere pile of grass". The grass which is loved and the disliked grass are different full noemata, constituted by different emotional attitudes.

Wang's understanding of the relation between valued $w u$ and emotional $y i$ is similar to Husserl's theory of feelings and valued noemata, and Wang also faces the danger of being understood as a relativist. This danger is even higher for Wang, for 
he often uses the phrase "non-distinction of good and evil" (wu-shan-wu-e 無善無惡 ). Thus, in his dialogue with Xue Kan, he carefully explains this notion himself:

Being attached to the non-distinction of good and evil, the Buddhists neglect everything and therefore are incapable of governing the world. The sage, on the other hand, in his non-distinction of good and evil, merely makes no special effort whatsoever to like or dislike, and is not perturbed in his vital force. (Wang 1963, 64)

Wang believes that the Buddhist principle cannot be used to govern the world because governing requires the distinction between what is harmful and what is beneficial, while Buddhism refuses to make this distinction. On the contrary, Confucians, including Wang, all believe that the highest ethical task is to rule the world properly. ${ }^{15}$ Hence, Wang insists that "[i]f weeds are harmful, according to principles they should be removed. Then remove them, that is all" (Wang 1963, 65). To remove some weeds, it is necessary that they are constituted as harmful, which is obviously an ethical value. Wang argues a valued thing should not be "artificially" made but should be correlated with an intention which follows "the tranquility of principles". In his view, Confucian sages do distinguish what is good from what is bad, but they do it by following some principles. Such principles mentioned by Wang are tian-li, and Wang believes that if a $y i$ is to be moral, it should follow such universal laws. As Wang says in a letter written in 1513:

(Wang) said, "Not to artificially like or dislike is not to make no liking or disliking at all. A person behaving so would be devoid of consciousness. To say "not to artificially make" merely means that one's liking and disliking (should) completely follow tian-li and that one does not go on to attach to that situation a bit of selfish thought." (Wang 1963, 64)

The “artificial liking and disliking” (zuo haowu 作好惡) means to make or to produce emotional $y i$ of liking and disliking. Such a $y i$ is only "made" according to one's private standards in Hobbes' sense so that it is opposed to tian-li which are universal. A sage, on the contrary, always loves what should be loved and hates what should be hated according to such principles. As was mentioned early in this section, for NeoConfucians, tian-li are both the foundations of morality. They determine the essence of values: for example, according to the principle of sheng-sheng, being beneficial for life is a positive value in a general sense. Also, when Wang argues that sages always like what should be liked according to tian-li, such principles can always serve to determine whether a particular $w u$ should be positive or negative. Tian-li can determine whether a particular $y i$ should be an act of liking or disliking. A $y i$ that is not artificially made is an emotional noesis that follows principles, whose structure is the same with moral acts within Husserl's axiological theory. For both philosophers, the highest ethical principles as universal and objective principles should be used to guide emotional acts in particular situations.

\footnotetext{
${ }^{15}$ For example, according to $D a-X u e$, to rule a kingdom properly and to bring peace to the world are the two highest achievements for one who is moral.
} 
Wang's explanation to Xue Kan's question regarding Buddhism can help us to clarify the correlation between cheng-yi and ge-wu. An insincere $y i$ is "artificially made", rather than following tian-li. In the letter that was mentioned above, Wang also argues that "the righteousness is to live with things, this means my heart can achieve its propriety" (Wang 2014, 175). What can be righteous or not is not the thing, but xin which "lives with (chu 處)" the thing. An improper emotional $y i$, as Kern points out, is a "selfish intentionality" (Kern 2010, 135). The implication is that the way through which this act loves or hates its noema is different from the way of tian-li. If xin properly loves what should be loved and dislikes what should be disliked, it achieves the righteousness or the propriety. A $y i$ of disliking that is coherent with tian-li is also be proper and correct, for such a $y i$ is radiated from a righteous xin. Also, since what is good is something that is liked, such a noema with a positive value can also be immorally and artificially constituted. For example, according to Wang's understanding of the principle of sheng-sheng, a yi of disliking some weeds when they are harmful to agriculture can be proper, while Xue Kan improperly dislikes the grass among his flowers. A flood of the Yellow River would be hated in ancient China, but that of the Nile would be loved in ancient Egypt. Both forms of $y i$ towards floods are proper, within the Confucian framework.

The term "proper" can shed light on Wang's understanding of human actions, named by Wang as affairs (shi 事). As was mentioned in Section 3, shi are also noemata. Wang maintains that correlated $y i$ of shi should also follow tian-li. For example, he claims that whether one should accept a gift or not is also a shi:

Some (gifts) should be accepted now but declined on other days. Others should be declined now but accepted on other days. If you are biased toward what you should accept now and go right on to accept everything or if you are biased against what you decline now and go right to decline everything, then this is setting the heart for or against things... How can it be called righteousness? (Wang 1963, 211-212)

Wang claims in this quotation that a gift can be righteously accepted. What can be righteous is a xin as the subject of emotional $y i$. A gift that should be received is a noema with a positive value of "being acceptable". Note that for Wang, the social norms such as the norm according to which one should accept or refuse a gift are not limited by historical, social, or ideological contexts but should be universal for the source of such norms is nothing but tian-li (Wang 1963, 74). That is to say, a shi which is constituted with a positive value can also be correct or incorrect, due to whether it is properly liked or disliked.

Therefore, it is necessary to distinguish what is bad and what ought to be bad: for Wang, anything that is disliked is bad for the one who hates it, while whether it ought to be bad is determined by tian-li. By saying that to ge-wu is to rectify $w u$, the notion "correct" is correlated with the notion "proper." The latter describes $y i$ which are coherent with tian-li. An "incorrect" thing is not necessarily a noema with a negative value but is constituted by an improper $y i$. What is correct is a proper yi as a good noesis. For the sake of convenience, we can also distinguish noeses valuing their 
noemata from evaluations of noeses themselves: a pile of weeds is valued as harmful or negative by its $y i$, while Xue's dislike towards some non-harmful weeds is evaluated to be improper. An incorrect $w u$ is not necessarily a disliked thing valued as negative, but its correlated yi must be evaluated as improper. Since different emotional $y i$ constitute different value-properties, it is proper to say that this process, as both ge-wu and cheng-yi, also changes $w u$ noematically through changing its noematic value.

\section{THE FUNCTION OF LIANG-ZHI FOR GE-WU}

According to Wang, ge-wu, as the fundamental method of moral effort, is to rectify an improper emotional intention. Through this process, its constituted valued object can also be made proper. Wang believes that if one performs the effort of ge-wu repeatedly in one's life, then finally he or she will be able to eliminate all selfish desires and acquire the complete power of his or her original moral capabilities. The function of the unity of ge-wu and cheng-yi is to polishing xin as a mirror. The problem is that to rectify an improper yi, one must know that it is inappropriate and immoral. Wang's close friend, Zhan Ruoshui (湛若水), suggests that this form of knowing may not be available for most people. He argues that even ancient wise people like Mo Zi (墨子) and Yang Zhu (楊朱) would believe that their yi are correct, while actually, they are acting improperly, for they are already troubled by si-yü (Zhan 1997, 571). This position of Zhan is similar to that of Zhu Xi, for if one who needs moral effort cannot know that a yi of him or her is immoral, then he or she will have to seek the help from knowledge. Wang's response to this difficulty is his later doctrine of liang-zhi, which is his new understanding of zhi-zhi. As was mentioned in the second section, he rejects Zhu Xi's theory, according to which only ge-wu is a process of zhi-zhi as the attempt to expand one's knowledge. Wang's strategy is to argue that $z h i$ 知 in zhi-zhi is liang-zhi, whose structure and function are different from knowledge in Zhu Xi's sense.

In recent years, scholars writing in Chinese were interested in Iso Kern's arguments that for Wang, liang-zhi has two meanings, one of which is similar to reflective noeses, whose noemata are other noeses belonging to the same ego. ${ }^{16}$ Though Kern's study itself might be problematic as many scholars suggested, it is evident that Wang himself does believe that one function of liang-zhi is to observe one's emotional yi. Wang agrees with a student of him, who claims that liang-zhi can know that an immoral $y i$ arises. Such incorrect acts "may be checked at the beginning, or controlled while they are in progress, or changed at the end" (Wang 1963, 138139). In a dialogue discussing liang-zhi with his student Nan Daji (南大吉), Wang argues that liang-zhi is like a bright mirror that can clearly show one's "faults in xin" (xin-guo 心過) (Wang 2014, 1301-1302). Such faults are immoral yi. One who may still have "faults in $x i n$ " is one who still needs moral effort to eliminate these faults.

${ }^{16}$ See Kern 1994; Chen 2014; Li 2014; Lin 2014; and Wu 2015. 
Thus, unlike Zhan who believe that people who are not sages cannot know that their intentional acts are immoral, Wang suggests that these people only lose their power of liking or disliking morally in many cases, but still hold their capability of recognizing that such $y i$ are not proper. By borrowing the term liang-zhi from Mencius to name such a capability of inner knowing as liang-zhi, Wang describes it as original for xin

Thus, Wang distinguishes two forms of original capabilities of xin: the ability to act morally, and the ability of self-observing. He argues that though the former can be concealed, the latter can never be destroyed (Wang 1963, 194). In a letter written in 1525 , Wang maintains that "only this clear self-knowing is liang-zhi, and to extend this liang-zhi by seeking self-satisfaction is zhi-liang-zhi" (Wang 2014, 220; 1963, 154 , and 167). Accordingly, the seeing of improper $y i$ is not sufficient for the moral effort: liang-zhi needs to be satisfied, which is to eliminate what is improper. Liang$z h i$, as self-observation, not only sees improper $y i$ but also guide people to rectify such yi. Cheng-yi under the guidance of liang-zhi is the process of zhi-liang-zhi. In other words, "the root of cheng-yi lies in zhi-liang-zhi (Wang 1963, 248), which indicates that cheng-yi is based on the process of following the "requirement" of liang-zhi. Liang-zhi "shows" improper $y i$ in one's $x i n$, and guides this person to rectify such $y i$.

The moral effort is, therefore, portrayed by Wang as a continuous process consists of the unity between ge-wu and cheng-yi, under the guidance of liang-zhi. Wang's theory of liang-zhi is a controversial topic. For example, philosophers like Wang Fuzhi (王夫之) and Gu Yan-wu (顧炎武) who lived in the late Ming Dynasty and early Qing Dynasty argue that Wang's doctrine of liang-zhi will make people only trust their strong impulses, and violate the Confucian principles. However, since the focus of this article is Wang's doctrine of ge-wu, it is sufficient to analyze the formal function of liang-zhi for ge-wu according to Wang's late thoughts.

\section{CONCLUSION}

My reading of Wang's doctrine of ge-wu as correcting things borrows Husserl's phenomenology of emotional noeses. Such a noetic act is also a valuing one, which constitutes an intentional object with some values as its noematic properties. As a higher noetic layer, an emotional noesis is founded on the mere presentation. Thus, the feeling as a noesis that changes the value property of its noema does not change the identification of the valued "mere thing".

According to Wang, a "correct" thing is something with a proper value-property, for it is properly constituted by an emotional yi. Since both liking and disliking can be correct, in particular contexts, negative and positive values can both be both "corrected" constituted as properties of $w u$.. The standard of distinguishing what is proper from what is improper is tian-li as ben-ti of xin. Though these principles as the original talent of xin can be concealed, its capability of self-observation cannot. This capability is liang-zhi. Wang's later doctrine of liang-zhi and zhi-liangzhi can make his earlier teaching of moral effort based on ge-wu more complete: ge-wu, the same with cheng-yi, is a continuous process under the guidance of liang-zhi. To follow the 
guidance of liang-zhi is the process of zhi-liang-zhi. The final purpose of the moral effort as ge-wu under the guidance of liang-zhi is to eliminate all si-yü which conceal the original substance of one's xin.

\section{ACKNOWLEDGEMENTS}

I should thank Dr. Harrington who helped me a lot when writing the earlier drafts of this article. I am also grateful for valuable comments on this paper from three anonymous referees, and for their precious time.

\section{REFERENCES}

Cai, Fang-lu 蔡方鹿 (1991), “Zhu-Xi-Xin-Tong-Xing-Qing-Shuo-Xin-Lun”《朱喜心统性情 说新论》[“A New Discussion On Zhu Xi's Doctrine [Xin Unites Xing and Feelings'], Kong-Zi-Yan-Jiu《孔子研究》[Studies on Confucius] (1991) 4: 74-78.

Cai, Ren-hou 蔡仁厚 (1983), Wang-Yang-Ming-Zhe-Xue 《王陽明哲學》[The Philosophy of Wang Yang-ming] (Taibei: Sanmin Shuju).

Chen, Lai 陈来 (1986), “Zhu-Xi-Zhe-Xue-De-Xin-Tong-Xing-Qing-Shuo” 《朱子哲学的心 统性情说》[“The Doctrine that 'Xin Unites Xing and Feelings' in Zhu Xi's Philosophy”], Zhe-Jiang-Xue-Kan《浙江学刊》[The Academic Journal of Zhejiang] (1986) 6: 76-78; 88.

- (2009), You-Wu-Zhi-Jing-Wang-Yang-Ming-Zhe-Xue-De-Jing-Shen《有无之境一王阳明 哲学的精神》 [The Spiritual Realms of Being and Non-Being: the Spirit of Wang Yangming's Philosophy] (Beijing: Shenghuo, Dushu, Xinzhi Sanlian Shudian).

Chen, Li-sheng 陈立胜 (2004), "Shi-Jian-Zhi-Wang-Yang-Ming-Yi-Ti-Guan-Zhong-De-TiZhi-Guan-De-Xian-Xiang-Xue-Fen-Xi《“视”、“见”、“知”一王阳明一体观中 的体知观的现象学分析》 [“Looking, Seeing, Knowing, a Phenomenological Study of the Notion of 'Seeing-as' in Wang Yang-ming's Understanding of Unification"], XianXiang-Xue-Yu-Lun-Li-Guo-Ji-Xue-Shu-Yan-Tao-Hui 《现象学与伦理学国际学术研讨 会》[Phenomenology and Ethos Conference]: 341-348.

- (2014), "Zai-Xian-Xiang-Xue-Yi-Yi-Shang-Ru-He-Li-Jie-Liang-Zhi-Dui-Geng-Ning-ZhiWang-Yang-Min-Liang-Zhi-San-Yi-Shuo-De-Fan-Si”《在现象学意义上如何理解良知 一对耿宁之王阳明良知三义说的反思》 [“How to Understand Liang-Zhi Phenomenologically: A Reflective Study of Iso Kern's Interpretation of the Three Meanings of Wang' Yangming's Liang-Zhi'], Zhe-Xue-Fen-Xi 《哲学分析》 [Philosophical Analysis] (2014) 4: 23-39.

Chen, Shao-ming 陈少明 (2014), “'Xin-Wai-Wu-Wu-Cong-Cun-Zai-Lun-Dao-Yi-Yi-JianGou 《心外无物一从存在论到意义建构》 [“'No Things Are External to xin': from an Ontology to a Constitution of Senses”], Zhong-Guo-She-Hui-Ke-Xue 《中国社会科学》 [Social Sciences in China] (2014) 1: 68-84.

Cheng, Zhong-ying 成中英 (2014): “Zhu-Xi-Yu-Zhang-Shi-De-Lun-Xue-Xing-Ti-QingYong-Yu-Xing-Ti-Xin-Yong-Dao-Xiang-Xin-Zhi-Jiu-Yong” 《朱喜与张栻的论学一性 
体情用心统与性体心用导向心之九义》[“Discussions between Zhu Xi and Zhang Shi: From The Use of the Original Substance by Xing by Feelings and Xin to the Nine Meanings of “Xin”" Si-Chuan-Shi-Fan-Da-Xue-Xue-Bao 《四川师范大学学报》 [Journal of Sichuan Normal University] (2014) 41.3: 5-14.

Hart, James (1992), The Person and the Common Life: Studies in a Husserlian Social (Boston: Kluwer Academic Publishers).

Hobbes, Thomas (1994), Leviathan (Indianapolis: Hackett Publishing Company).

Husserl, Edmund (1950), Ideen zu Einer reinen Phanomenologie und Phanomenologischen Philosophie, Buch I (The Hague: Martinus Nijhoff).

- (1952), Ideen zu einer reinen Phänomenologie und phänomenologischen Philosophie. Zweites Buch, Phänomenologische Untersuchungen zur Konstitution (The Hague: Martinus Nijhoff).,

- (1984), Logische Untersuchungen, Zweiter Teil (The Hague, Netherlands: Martinus Nijhoff).

- (1988), Vorlesungen über Ethik und Wertlehre, edited by Ullrich Melle (Dordrecht: Kluwer Academic Publishers).

- (1989), Ideas Pertaining to a Pure Phenomenology and a Phenomenological Philosophy, Second Book: Studies in the Phenomenology of Constitution, translated by Richard Rojcewicz and Andre Schuwer (Boston: Kluwer Academic Publishers).

- (1998), Ideas Pertaining to a Pure Phenomenology and a Phenomenological Philosophy, First Book, translated by Fred Kersten (Boston: Kluwer Academic Publishers).

- (2001), Logical Investigations, translated by John N. Findlay, edited by Dermot Moran (New York: Routledge).

Ivanhoe, Philip J (2009), trans, Readings from the Lu-Wang School of Neo-Confucianism. (Indianapolis: Hackett Publishing Company).

Jung, Hwa Yol (2002), Transversal Rationality and Intercultural Texts: Essays in Phenomenology and Comparative Philosophy (Athens: Ohio University Press).

Kern, Iso (1994), "Die Umwandlung und Zweideutigkeit von Wang Yangmings Begriff des 'ursprunglichen Wissens'," Asiatische Studien/Etudes Asiatiques: Zeitschrift der Schweizerischen Asiengesellschaft 48.4: 1119-1141.

- (2010), Das Wichtigste im Leben: Wang Yangming (1472-1529) und seine Nachfolger über die „Verwirklichung des ursprünglichen Wissens “ (Basel: Schwabe Verlag).

Li, Ming-Hui 李明辉 (2014), “Geng-Ning-Dui-Wang-Yang-Ming-Liang-Zhi-Shuo-DeQuan-Shi” 《耿宁对王阳明良知说的阐释》 [“Iso Kern's Interpretation of Wang Yangming's Doctrine of Liang-zhi”], Zhe-Xue-Fen-Xi 《哲学分析》[Philosophical Analysis] (2014) 4: 40-50.

Liang, Qi-chao 梁啟超 (1968), Wang-Yang-Ming-Zhi-Xing-He-Yi-Zhi-Jiao《王陽明知行合 一之教》[Wang Yang-ming's Doctrine of the Unity of Knowing and Acting] (Taipei: Taiwan Zhonghua Book Company ).

Lin, Yue-hui 林月惠 (2014), “Yang-Ming-Yu-Yang-Ming-Hou-Xue-De-Liang-Zhi-GaiNian-Cong-Geng-Ning-Lun-Wang-Yang-Ming-Liang-Zhi-Gai-Nian-De-Yan-Bian-Ji-QiShuang-Yi-Xing-Tan-Qi”《阳明与阳明后学的良知概念一从耿宁论王阳明良知概念 的演变及其双义性谈起》 [“Liang-Zhi in Wang Yangming and the Later Yang-Ming School: From Iso Kern's 'Die Umwandlung und Zweideutigkeit von Wang Yangmings Begriff des ursprunglichen Wissens"'], Zhe-Xue-Fen-Xi 《哲学分析》[Philosophical Analysis] (2014) 4: 4-22. 
Loidolt, Sophie (2012), “A Phenomenological Ethics of the Absolute Ought: Investigating Husserl's Unpublished Ethical Writings," in Ethics and Phenomenology, edited by Mark Sanders and J Jeremy Wisnewski, 9-38 (New York: Lexington Books).

McIntyre, Ronald, and Woodruff, David (1989), "Theory of Intentionality," in Husserl's Phenomenology: A Text Book, edited by William McKenna, 147-79 (Washington D. C.: Center for Advanced Research in Phenomenology and University Press of America).

Mou, Zong-san 牟宗三 (2003), Cong-Lu-Xiang-Shan-Dao-Liu-Ji-Shan 《從陸象山到劉茷 山》[From Lu Xiang-shan to Liu Jishan], Mou-Zong-San-Xian-Sheng-Quan-Ji 《牟宗 三先生全集》 [Collected Works of Teacher Mou Zongsan] 8 (Taipei: Linking Book).

Peucker, Henning (2007), "Husserl's Critique of Kant's Ethics," Journal of the History of Philosophy 45.2: 309-19.

- (2008), "From Logic to the Person: An Introduction to Edmund Husserl's Ethics." The Review of Metaphysics 62.2: 307-25.

Wang, Yang-ming 王陽明(Wang Shou-ren 王守仁) (1963), Instructions for Practical Living and Other Neo-Confucian Writings, translated and edited by Chan Wing-tsit (New York: Columbia University Press).

- (2014), Wang-Yang-Ming-Quan-Ji 《王陽明全集》[Complete Works of Wang Yangming], edited by $\mathrm{Wu}$ Guang, Qian Ming, Dong Ping, and Yao Yan-fu (Shanghai: Shanghai Guji Book Company).

Wu, Zhen 吴震 (2015), “Lue-Yi-Geng-Ning-Dui-Wang-Yang-Ming-Liang-Zhi-Zi-Zhi-ShuoDe-Quan-Shi-Jiu-Xin-De-Xian-Xiang-Geng-Ning-Xin-Xing-Xian-Xiang-Xue-Lun-Wen-

Ji-Er-Tan” 《略议耿宁对王阳明良知自知说的诠释一就〈心的现象：耿宁心性现象学 论文集>而谈》[On Kern's Interpretation of Wang Yang-ming's Doctrine of SelfAwareness of Liang-zhi: Talking About Kern's The Phenomenon of Xin] Xian-Dai-ZheXue [Modern Philosophy] 《现代哲学》(2015) 1: 118-125.

Xiang, Shi-ling 向世陵 (2012), "Ren-Xin-Jue-Xin-Yu-Ben-Ti-Zhu-Xi-Xin-Lun-San-Yi《仁 心、觉心与本体一朱喜心论三议》 [Three Discussions on Zhu Xi's Doctrine of Xin]” Hu-Nan-Da-Xue-Xue-Bao 《湖南大学学报 (社会科学版) 》[Journal of Hunan University (Social Sciences)] (2012) 6: 5-10.

$\mathrm{Xu}$, Shen 許慎 (1981), Shuo-Wen-Jie-Zi《说文解字》 [Explanation of Characters] (Beijing: Zhonghua Book Company).

Zahavi, Dan (2003), Husserl's Phenomenology, (Stanford: Stanford University Press).

Zhan, Ruo-shui 湛若水 (1997), Zhan-Gan-Quan-Xian-Sheng-Wen-Ji《湛甘泉先生文集》

[Collected Essays of Zhan Gan-quan], Si-Ku-Quan-Shu-Cun-Mu-Cong-Shu 《四庫全書 存目叢書》[Series of Siku Quanshu Cunmu] 56 (Ji-nan: Qi-lu Book Company)

Zhang, Wei 张伟 and Xu, Xin (2009), “The Foundation of Phenomenological Ethics: Intentional feelings," Frontiers of Philosophy in China 4.1: 130-42.

Zhang, Zai-lin 张再林 (1997), “Hu-Sai-Er-'Yi-Xiang-Xing'-De-Li-Lun-He-Wang-YangMing-De-'Yi'-De-Xue-Shuo”《胡塞尔 “意向性” 的理论和王阳明的 “意” 的学说》 ["Husserl's Intentionality and Wang Yang-ming's Doctrine on Yi"], Qing-Hai-She-HuiKe-Xue 《青海社会科学》[Qing-hai Social Sciences] (1997) 4: 61-66.

Zhao, Yan 赵炎 (2017) “Zhu-Xi-De-Zun-De-Xing-Xin-Zhi-Ben-Ti-Yu-Xin-Zhi-Fa-YongCong-Ming-Jing-Zhi-Yu-Kan-Zhu-Zi-Yu-Lu-Wang-Zhi-Yi-Tong” 《朱喜的尊德性一本 体与心之发用：从明镜之喻看朱子与陆王之异同》[“Zhu Xi's Doctrine of 'Respecting Virtues and Xing,': Ben-Ti and Uses of Xin, Using the Metaphor of Mirror to 
Discuss the Similarities and Differences Between the Doctrine of Zhu-Xi and that of Wang and Lu, "] She-Hui-Ke-Xue-Zhan-Xian 《社会科学战线》[Social Science Front] (2017) 12: 21-29.

Zhu, Xi 朱喜 (1779), Hui-An-Ji《晦庵集》[Collected Works of Zhu Xi] (Beijing: Si-KuQuan-Shu).

— (1986), Zhu-Zi-Yu-Lei《朱子語類》[Recorded Conversations of Zhu Xi] (Beijing: ZhongHua Book Company).

- (2015), Si-Shu-Zhang-Ju-Ji-Zhu 《四書章句集註》[Collected Commentaries on the Four Books] (Beijing: Zhong-Hua Book Company). 